Vermeulen, L., Schäfer, W., Pavlic, D.R., Groenewegen, P.P. Community orientation of general practitioners in 34 countries. Health Policy: 2018, 122(10), 1070-1077

\begin{tabular}{|l|l|}
\hline $\begin{array}{l}\text { Postprint } \\
\text { Version }\end{array}$ & 1.0 \\
\hline Journal website & $\begin{array}{l}\text { https://www.sciencedirect.com/science/article/pii/S0168851018301970?v } \\
\text { ia\%3Dihub }\end{array}$ \\
\hline Pubmed link & https://www.ncbi.nlm.nih.gov/pubmed/30041912 \\
\hline DOI & 10.1016/j.healthpol.2018.06.012 \\
\hline
\end{tabular}

This is a NIVEL certified Post Print, more info at http://www.nivel.eu

\title{
Community orientation of general practitioners in 34 countries
}

\author{
Lisa VermeUlen ${ }^{\mathrm{A}, \mathrm{B}}$, WiLlemijn SCHÄFER ${ }^{\mathrm{A}, \mathrm{C}, \mathrm{D}}$, DANICA Rotar PAVLIC ${ }^{\mathrm{E}}$, PETER
}

GROENEWEGEN $^{\mathrm{A}, \mathrm{F}, *}$

${ }^{a}$ Netherlands Institute for Health Services Research, Otterstraat 118, 3513 CR, Utrecht, The Netherlands

${ }^{\text {b} Y o n g ~ B . V ., ~ J a n ~ S t e e n l a a n ~ 127, ~} 6717$ TB, Ede, The Netherlands

'Northwestern University, Feinberg School of Medicine, Department of Social Medical Sciences, 625 N. Michigan Ave, 27th floor, Chicago, IL, 60611, USA

dNorthShore University Health System, Department of Family Medicine, Research Institute, 1001 University Place, Evanston, IL, 60201, USA

${ }^{e}$ Department of Family Medicine, University of Ljubljana, Poljanski nasip 58, 1000, Ljubljana, Sloveniaf Utrecht University, The Netherlands

\section{HighLIGHTS}

- There is a large international variation in community orientation between GPs.

- In countries with a defined patient list GPs are more community oriented.

- GPs more active in prevention and multidisciplinary cooperation are more community oriented.

- GPs using medical records to make overviews are more community oriented.

- GPs in areas with more ethnic minority people are more community oriented.

\begin{abstract}
General practitioners (GPs) are frontline health workers. They should be sensitive to the health needs of the community in addition to caring for patients that visit their practice. Due to changes in demography, epidemiology, ecology and healthcare policy, a community orientation becomes more important. Our research question is: to what extent does community orientation of GPs vary between countries and GPs and how can this variation be explained? We use cross-sectional survey data from the QUALICOPC study, conducted among over 7000 GPs in 34 countries. Community orientation was measured through a scale constructed from three survey questions on whether GPs would take action when confronted with: repeated accidents in an industrial setting, frequent respiratory problems in patients living near a certain industry, and repeated cases of food poisoning in the local community. Independent variables are at
\end{abstract}


healthcare system level and GP or practice level. Data were analysed using linear multilevel regression analysis. Community orientation varies between GPs and countries. Community orientation is more frequent in healthcare systems with a list system, among self-employed GPs, those using medical records to make overviews, and those more active in prevention and multidisciplinary cooperation. GPs in rural areas and areas with more people from ethnic minorities are more community oriented. Based on the variation between countries and GPs, we would like to raise awareness and underline the importance of multidisciplinary cooperation.

\section{INTRODUCTION}

Current changes in demography, epidemiology and ecology require general practitioners (GPs) to strengthen their community oriented approach. Community orientation of GPs and - broader - of primary care, means that care providers assume responsibility for the population in their practice area instead of only for those people that visit the practice. Community oriented service provision is sensitive to the health needs of the population [1]. This is facilitated by insight in population health issues, involvement of GPs in the community and involvement of the community in health related issues [2]. In this article we try to explain differences in community orientation of GPs in 34 countries.

A community oriented approach of GPs has become more important for several reasons. Ageing of the population leads to higher prevalence of chronic disease and multi-morbidity [3]. Chronic diseases are to a large extent life style related. People increasingly age in place [4], partly due to policies to contain long-term care costs [5] and partly due to preferences of elderly people themselves [6]. These changes in demography and epidemiology add to long-known ecological hazards, such as environmental pollution and occupational risks. They can be observed by GPs by looking into patterns of ill-health in their patient population. According to Wonca Europe (the scientific and academic association of European GPs) one of the core competences of GPs is 'the ability to reconcile the health needs of individual patients and the health needs of the community in which they live in balance with available resources' [1]. Consequently, taking responsibility only for those who visit the practice is not sufficient. A responsive, active and outreaching approach is needed. Primary care and health care in general are shifting from disease oriented care, e.g. in the form of disease management programmes [7] to patient oriented care where patients are seen as more than their disease and finally towards people-centred care [8]. The latter includes both an orientation towards persons and towards the local community [9].

In the definition of its founders, Community Oriented Primary Care (COPC) is defined by the following elements: the use of epidemiology and clinical skills to characterize the health needs of the community, assuming responsibility for a defined population, clear-defined programs to address communities' health needs, community involvement, and accessibility to services [2]. Against this background, we analysed data from a multi-country survey among GPs to answer the following research questions:

- How does community orientation vary between countries and GPs or practices? 
- How can this variation be explained by characteristics of GPs and characteristics of the organisation of their practices and of health care systems?

We use secondary data, collected in the international QUALICOPC study. In this study, community orientation has been measured by three survey questions on whether GPs would take action when confronted with repeated accidents in an industrial setting, frequent respiratory problems in patients living near a certain industry, and repeated cases of food poisoning in the local community. This measurement is less encompassing than the concept of COPC in its original formulations [2], but can be seen as approximation of the phenomenon.

\section{HYPOTHESES}

We have developed a number of hypotheses to guide the analyses. They relate to the potential influence of characteristics of the GPs, their practice, and the healthcare system they work in, as shown in Fig. 1.

\section{[FIGURE 1]}

At the country level, we expect that characteristics of thehealthcare system, the political composition of governments, and economic resources are related to the extent to which GPs have adopted a community oriented approach.

\subsection{Health care system characteristics}

GPs in countries with a stronger structure of primary care (PC) are hypothesized to be more community oriented, because they have invested more in PC than GPs in countries with weaker PC structures [10].

H1 GPs community orientation is stronger in countries with stronger primary care

In countries with a national health system (NHS) we expect more community orientation compared to countries with social health insurance (SHI) and transitional systems, because the centralized structure of a national health system facilitates implementation of organizational changes in general [11].

H2 GPs community orientation is higher in NHS systems than in SHI or transitional systems

In countries that have a patient list system, GPs are responsible for a defined population, which is a prerequisite for COPC $[2,12]$. Therefore, we argue that GPs in countries with an obligatory list system are more prone to community orientation.

H3 GPs community orientation is higher in countries with an obligatory patient list system

\subsection{Political composition}

Strong primary care requires active policies [13] and countries that have a left-wing government are more willing to intervene [14]. Previously an association has been found with strength of primary care [10]. COPC is a strategy that is used to create access to healthcare for all societal groups, and may thus be seen as an equalizing strategy [15] that will therefore likely be endorsed more by left-wing political parties [11]. 
Vermeulen, L., Schäfer, W., Pavlic, D.R., Groenewegen, P.P. Community orientation of general practitioners in 34 countries. Health Policy: 2018, 122(10), 1070-1077

$\boldsymbol{H} 4$ GPs community orientation is higher in countries with a longer history of leftwing parties in government

\subsection{Economic resources}

Traditionally, COPC developed in lower and middle income countries. The urgency to provide health care within a small budget by focussing on COPC is stronger in these countries [16].

H5 GPs community orientation is higher in countries with lower GDP

At the level of GP practices, we expect that structural aspects of the practice organization, the available resources and working style [17] are related to community orientation of GPs working in these practices. Moreover, we expect the environment in which GPs perform their tasks are related to community orientation.

\subsection{Structure of the practice}

Previous research $[18,19]$ has indicated that self-employment is associated with greater GP involvement in non-basic general practice and greater feelings of responsibility for outcomes of the practice in general. Community oriented practice is an example of a service presently not basic to general practice, and it requires a sense of responsibility for the health of a population. Therefore, it is argued that selfemployed GPs are more community oriented than salaried GPs.

\section{H6 GPs community orientation is higher for self-employed GPS than for salaried GPS}

We expect that GPs in fee-for-service systems are less inclined to implement COPC than GPs in salaried or capitation payment systems, because GPs in capitation and salary systems receive a fixed amount of money respectively per patient or per hour worked and can therefore allow themselves to spend time on COPC without decrease in income. Additionally, it is expected that GPs in capitation payment systems, since they have an incentive to keep the patients tied to their practice, are more likely to be involved in COPC than GPs in salaried payment systems.

H7 GPs community orientation is lowest with fee-for-service payment, higher with salaried payment and highest with capitation payment

\subsection{Resources of the practice}

Electronic medical records may be used to generate overviews to gain insight in population health problems, which is a condition for COPC.

$\mathrm{H8}$ GPs community orientation is higher if they use electronic medical records to generate overviews of their patient population

\subsection{Working style}

Preventive care usually addresses people irrespective of whether they are already a patient; therefore, practices that have a more preventive way of working might also show a stronger community orientation $[20,21]$.

H9 GPs community orientation is higher when they provide more services in preventive care 
Vermeulen, L., Schäfer, W., Pavlic, D.R., Groenewegen, P.P. Community orientation of general practitioners in 34 countries. Health Policy: 2018, 122(10), 1070-1077

Interdisciplinary cooperation opens up to address broader problems than just medical problems and opens up sources of information about community health and ways of dealing with the community's health needs [22,23].

H10 GPs community orientation is higher when they work interdisciplinary

\subsection{Task environment (the area where a practice is located)}

In rural areas, the number and scale of GP practices is usually smaller and thus it may be easier to know the population and their living circumstances and therefore facilitate a community orientation [24].

\section{H11 GPs community orientation is higher for GPs in rural areas}

In areas with a disadvantaged population or in areas with larger shares of migrants or ethnic populations access to healthcare is often lower $[25,26]$. Community orientation may help GPs to adopt a more inclusive approach.

H12a GPs community orientation is higher in areas with a higher percentage of socially disadvantaged patients or patients from ethnic minorities

At the level of GPs we formulated two hypotheses:

GPs having no other paid activities could be more community oriented because there is no 'time competition' from other paid activities.

H13 GPs community orientation is higher when they have no other paid, professional activities

Gender of the GP may be related to their community orientation, although no direction can be specified; female GPs could be more community oriented as a result of a more communal [27] and preventive attitude [28], but they could also be less community oriented due to more demands from family care and household tasks $[27,29]$. We therefore have no specific hypothesis about GP gender.

\section{MATERIALS AND METHODS}

\subsection{Data}

The data on community orientation of GPs, GP practice and GP characteristics were collected in the EU co-funded QUALICOPC study (see Box 1) [30]. We use information from the survey among GPs in 34 countries, three of which are outside Europe and five European but not EU Member States. 7183 GPs participated in the survey; varying from 70 respondents in Malta to 535 in Canada. The development of the questionnaire and the data collection have been described elsewhere $[31,32]$.

\section{[BOX 1]}

\subsection{Measurements}

The dependent variable was constructed from the QUALICOPC GP questionnaire. The questionnaire was designed to evaluate the strength of primary care [33] and three questions were added to get an impression of community orientation of GPs. These questions were based on the current literature: "If you were confronted through your patient contacts with the following occurrences, would you report this (for instance to an authority)? 
- repeated accidents in an industrial setting,

- frequent respiratory problems in patients living near a certain industry,

- repeated cases of food poisoning among people living in a certain district".

The answering categories were: yes, probably yes, probably not, no, and don't know. Strength of the PC structure was measured using data from Kringos [33] in which countries were categorized on a scale from 1 to 3 for which $1=$ weak PC structure and $3=$ strong PC structure. Type of healthcare system was characterized in three groups: national health systems, social health insurance systems and transitional systems [[34], [35], [36]]. Political composition of governments was measured following Kringos [10], using the weighted number of years left-wing parties were in power in the period 1960-2014 [37]. Whether health care system have a patient list system, was mainly taken from Kringos et al [38] for the European countries. For the non-European countries we refer to [[39], [40], [41]]. GDP per capita was taken from the World Bank

(http://databank.worldbank.org.proxy.library.uu.nl/data/reports.aspx? source=2\&serie $\mathrm{s}=$ NY.GDP.PCAP.PP.KD\&country, data for 2011).

The independent variables to test the hypotheses at GP/practice level were all taken from the GP questionnaire of the QUALICOPC study. So were three GP/practice level control variables (GP age, whether GPs receive financial incentives for preventive activities, and whether they share an accommodation with other GPs).

\subsection{Statistical analysis}

Because of the nested structure of the data, multilevel linear regression analysis was applied. We used a multi-response model with the three items that constitute the dependent variable at the lowest level, nested within GPs as second level and within countries as highest level. Because only one GP per practice was invited to participate, the GPs and their practices form one level. We applied a multi-response model because the three items are correlated (correlation coefficients between 0.64 and 0.71).

To avoid loss of observations due to missing values, we included dummy variables for the missing values in the independent variables. None of these dummies were significant; hence we don't report them in the tables.

The following modelling strategy was used. We first estimated an empty model (Model 0) to evaluate the variation in our outcome at GP/practice level and country level. Model 1 contains the control variables and in model 2 the GP and practice characteristics from our hypotheses are added. Model 2 is the baseline model for the evaluation of the country level variables. Due to the (relatively) small number of countries, we can only add few country characteristics at the same time to avoid over-determination. GDP per head, as operationalisation economic resources of country, is not only used to evaluate the hypothesis that less economic resources coincide with more community orientation, but can also be seen as an important confounder at country level. Model 3 contains GDP per head in addition to the GP and practice variables. This is the baseline model for the other country characteristics that are added and removed again one by one: in Model $3 \mathrm{~A}$ the strength of the structure of primary care is added; in Model 3B the structure of the health system; in Model 3C whether a list system is used; and finally in Model 3D the political composition of the government is added. 
We will report Model 0 and Model 2 and leave out Model 1, because it does not add more information than Model 2. In reporting the coefficients of the country variables, we leave the GP level coefficients out, because they are hardly affected by including the country level variables.

A significance level of $\mathrm{p}<0.05$ for GP/practice variables and $\mathrm{p}<0.10$ for country level variables (because of the small number of observations at country level) was used.

\section{RESULTS}

The countries in our study substantially differ with respect to community orientation. GPs from Norway, Turkey, Spain and Italy perceived themselves as very community oriented. On the other part of the spectrum there are Cyprus, Estonia, Hungary and Germany (Fig. 2). Of the non-European countries Canada and Australia are in the lower third and New Zealand in the upper third of the distribution.

\section{[FIGURE 1]}

The variation between countries in the empty model is $13 \%$ (Table 1; random part).

\section{[TABLE 1]}

The fixed part of Table 1 shows that GPs who use their medical records to generate overviews of the practice population are more community oriented. GPs who more often meet with other primary care professionals and those who more often ask medical specialists for advice are more community oriented. GPs in mixed urban/rural or rural areas and GPs who have their practice in an area with above average numbers of people from ethnic minorities are more community oriented than those in big (inner) cities or those with below average numbers of people from ethnic minorities. GPs who reported to be more active in the field of prevention are more community oriented. Those who have other paid professional activities are also more community oriented. Self-employed GPs are more community oriented compared to salaried GPs. Of the control variables working in a shared accommodation with other GPs is negatively related to community orientation.

GPs in the former communist countries - also denoted as transitional health care systems - are less community oriented compared to those in national health service system (Table 2). Of the other country variables only whether or not GPs in general have a defined patient list, is related to community orientation.

\section{[TABLE 2]}

Although we found a number of significant relationships between GP or practice characteristics and community orientation, the explanatory power in terms of reduced variance is only small. This can be seen in the small decrease in GP level variance in model 2 compared to the empty model (Model 0). Whether or not GPs have a patient list explains around $10 \%$ of the variation between countries (comparing the country level variance in Model 3 with that in Model 3C).

\section{DISCUSSION}

In this article we have developed and tested a set of hypotheses about the community orientation of GPs. The hypotheses addressed differences between countries, 
between GP practices and between GPs. As regards country characteristics, our hypotheses about the strength of primary care, about the left-wing government and about economic resources were refuted. The hypothesis about national health systems is partly corroborated. The role of these health system characteristics is not specific for community orientation; however, if national health policy makers have focused on introducing more community oriented primary care, organisational changes and specific incentives may be more easy to introduce in a more centralized health system. The hypothesis about having a patient list system is corroborated. At the level of the GP practices we have looked at the structure, resources, usual ways of working and task environment. Concerning the structural aspects of the practice, we found that capitation payment was not related to community orientation. We found that self-employed GPs were more community oriented. Employment status in itself is not related to community orientation; however, if incentives for a pro-active and outreaching approach in primary care would be introduced, in general selfemployed GPs are more likely to act on these incentives. Using the medical record system as a resource to generate overviews of the patient population is related to community orientation, as hypothesized. The hypotheses about the working style in the area of prevention and interdisciplinary cooperation were corroborated.

Two of the hypotheses about the task environment in which GPs do their work were corroborated: in more rural areas and in areas with more people from ethnic minorities we find a stronger community orientation. The hypothesis about the relationship with a disadvantaged population was refuted. Finally we formulated two hypotheses about characteristics of the GPs. Gender, for which we had no specific hypothesis, turned out to be unrelated to community orientation. Having other paid professional activities was related to community orientation but in the opposite way to what we hypothesized. Although some of our hypotheses were corroborated, the share of the GP level variance that was explained is small; the explained country level variance was higher. This means that there are other influences, not captured by our hypotheses and operationalizations, that cause the variation between GPs and countries. It also means that the effects of the variables that are related to the community orientation of GPs are small.

The subject of this study - community orientation of GPs - is important and expected to become even more important. This is related to changes in demography, epidemiology and ecology, as argued in the introduction. Although GPs are the core professionals in primary care in the countries studied, primary care, and COPC in particular, are broader than GP care. However, the study does assess collaboration within primary care in relation to community orientation. A reorientation of the model of care and change in educational policy are needed to implement a broader conception of primary care and to cope with these changes. A focus on the community, inter-professional education and involvement of the local population will build legitimacy, transparency and trust in health policies and governments. Modern health policies and interventions have to be designed and adapted to the local context, and the values and preferences of the people. Care should be coordinated around people's needs, respect their preferences, and allow for their participation in health affairs. In a broad sense community orientation is also important because of the increasing reliance of many older and frail people on informal carers. Primary care needs to involve informal carers and to monitor their coping ability. 
GPs in countries with a list system are more community oriented. These GPs are responsible for a defined population and are in a position to observe the phenomena that we used to measure community orientation. They can do this by evaluating the health problems presented to them via their electronic medical records. Clinical experience of one of the authors (DRP) showed that after an environmental incident worried people from the practice population visited the primary care practice to get information about possible intoxication.

There is some evidence that community oriented primary care yields positive health effects [42], but in this field more research is needed.

Our study has implications for health human resource policies. A shift towards COPC requires changes in the (primary) health workforce $[43,44]$. Health care providers have to learn how to adopt a community oriented approach. The mix of needed competences to do so might differ from the current profile of primary care practices. Practices need a broader range of skills, e.g. by including social workers in primary care teams. Moreover interdisciplinary cooperation is important. Current educational practices are not tuned to multidisciplinary education and practice. Educational implications of community oriented primary care have been emphasized in the literature [[45], [46], [47], [48]]. Wonca Europe has defined a community oriented way of working as a core competences of GPs [1].

This study has some strengths and weaknesses. A weakness is the measurement of community orientation. As the QUALICOPC study was not designed to study the implementation of community oriented primary care in countries, we had to work with an imperfect measurement of community orientation. Community orientation is a broader concept than that captured by reacting on external signals. It also includes defining the social characteristics of the community, identification of health problems, and involving the community [49]. It also includes a link to public health $[50,51]$. We did not have systematic information about the organisation of public health and social care and how these relate to community orientation. A strong local organisation of public health might cover the community situations that were used to operationalise community orientation. However, local public health tasks might also be part of the tasks of GPs, as is the case in Norway. In this country the community orientation of GPs is high.

Community orientation was measured by self-reports of GPs which might be subject to bias. We haven't been able to find independent validation for the self-reported GP community orientation. However, in another analysis of QUALICOPC data selfreports of GPs on the range of services that they report to offer were positively related to patients' perceptions of accessibility, continuity, and comprehensiveness of care, and involvement in decision making [52].

Given the nature of the data we are not able to say anything about the causal nature of the associations we have found. We can say that some of the hypotheses imply a causal nature of the relationship (such as the hypothesized link to a list system and capitation payment), whereas other hypotheses are more of a co-occurrence type (such as the hypothesis about preventive activities) and some associations may be the result of self-selection (such as the association with more than average numbers of people from ethnic minorities). Moreover, at least some of the hypotheses are interrelated. For example, health system characteristics influence the organisation of GP practice and both are related to community organisation. 
A strength of our study is the relatively large number of countries and the large numbers of GPs and practices. The large number of countries and GPs and the richness of the data in other respects justify their use in a secondary analysis. Our analysis was guided by a set of hypotheses about different levels of potential influence on community orientation.

\section{CONCLUSIONS}

Our study shows that countries vary in community orientation of GPs. In particular for policy it is important that we found relationships with having a list system, the employment status of GPs, using medical records to inform practice policies, a focus on prevention and multidisciplinary cooperation. We also found relations with the task environment. This suggests that community orientation can be influenced both by national policies and by policies of the practices themselves. New incentives and regulatory conditions should be brought in place if we want primary care to develop further in the direction of community oriented care.

Educational policy is also important. Education of the future health workforce should give attention to community orientation, including ways to involve the local population in primary care. People-centredness can be enhanced by teaching primary care professionals to focus on the community, to emphasize inter-professional education and teaching how to involve the local population in primary care.

\section{Conflict of interest statement}

None.

\section{Acknowledgements}

This article is based on the QUALICOPC project, co- funded by the European Commission under the Seventh Framework Programme (FP7/2007-2013) under grant agreement 242141 .

The authors thank their partners in the QUALICOPC project; J. De Maeseneer, J. Detollenaere, L. Hanssens, S. Willems (Belgium); S. Greß, S. Heinemann (Germany); G. Capitani, S. De Rosis, A.M. Murante, S. Nuti, C. Seghieri, M. Vainieri (Italy); W. Boerma, D. Kringos, M. van den Berg, T. van Loenen (the Netherlands). In addition, the authors thank the coordinators of the data collection in each country.

\section{REFERENCES}

[1] Wonca Europe The European definition of general practice/ family medicine Revised edition (2011)

http://www.woncaeurope.org/sites/default/files/documents/Definition\%203rd\%20ed\%202011 \%20with\%20revised\%20wonca\%20tree.pdf

[2] S.L. Kark, E. Kark An alternative strategy in community health care: community-oriented primary health care Israel Journal of Medical Sciences, 19 (8) (1983), pp. 707-713

[3] B. Starfield Challenges to primary care from co-and multi-morbidity Primary Health Care Research \& Development, 12 (1) (2011), pp. 1-2

[4] H.-W. Wahl, S. Iwarsson, F. Oswald Aging well and the environment: toward an integrative model and research agenda for the future The Gerontologist, 52 (2012), pp. 306-316

[5] J.A. Maarse, P.P. Jeurissen The policy and politics of the 2015 long-term care reform in the Netherlands Health Policy, 120 (3) (2016), pp. 241-245,

10.1016/j.healthpol.2016.01.014 
Vermeulen, L., Schäfer, W., Pavlic, D.R., Groenewegen, P.P. Community orientation of general practitioners in 34 countries. Health Policy: 2018, 122(10), 1070-1077

[6] K.D. Doekhie, A.J.E. De Veer, J.J.D.J.M. Rademakers, F.G. Schellevis, A.L. Francke Ouderen van de toekomst. Verschillen in de wensen en mogelijkheden voor wonen, welzijn en zorg NIVEL, Utrecht (2014)

[7] S. Gress, C.A. Baan, M. Calnan, T. Dedeu, P. Groenewegen, H. Howson, et al. Coordination and management of chronic conditions in Europe: the role of primary care position paper of the European Forum for primary care Quality in Primary Care, 17 (2009), pp. $75-86$

[8] K.V. Stein, E. Stukator Barbazza, J. Tello, H. KlugeTowards people-centred health services delivery: a framework for action for the World Health Organisation (WHO) European region International Journal of Integrated Care, 13 (2013), Article e058

[9] J. De Maeseneer, C. Van Weel, L. Daeren, C. Leyns, P. Decat, P. Boeckxstaens, et al .From "patient" to "person" to "people": the need for integrated, people-centered healthcare International Journal of Person Centered Medicine, 2 (2012), pp. 601-614

[10] D. Kringos, W.G.W. Boerma, J. Van der Zee, P.P. Groenewegen Political, cultural and economic foundations of primary care in Europe Social Science and Medicine, 99 (2013), pp. $9-17$

[11] T. Tenbensel, S. Eagle, T. Ashton Comparing health policy agendas across eleven high income countries: islands of difference in a sea of similarity Health Policy, 106 (1) (2012), pp. 29-36

[12] J. De Maeseneer, A. Derese Community-oriented primary care European Journal of General Practice, 4 (2) (1998), pp. 49-50, 10.3109/13814789809160791

[13] P.P. Groenewegen, J. Dixon, W.G.W. Boerma The regulatory environment of general practice: an international perspective R.B. Saltman, R. Busse, E. Mossialos (Eds.), Regulating entrepreneurial behaviour in European health care systems., Open University Press, Buckingham/Philadelphia (2002)

[14] G.P. Westert, P.P. Groenewegen Regional disparities in health care supply in eleven European countries: does politics matter? Health Policy, 47 (1999), pp. 169-182

[15] R.L. Williams Motherhood, apple pie, and COPC Annals of Family Medicine, 2 (2) (2004), pp. 100-102

[16] S. Tollman Community oriented primary care: origins, evolution, applications

Social Science \& Medicine, 32 (6) (1991), pp. 633-642

[17] P.A. Lamarche, M.D. Beaulieu, R. Pineault, A.P. Contandriopoulos, J.L. Denis, J. Haggerty Choices for change: the path for restructuring primary healthcare services in Canada Canadian Health Services Research Foundation, Ottawa (2003)

[18] W. Boerma, J. Van der Zee, D.M. Fleming Service profiles of general practitioners in Europe. European GP task profile study British Journal of General Practice, 47 (1997), pp. 481-486

[19] P. Crampton The ownership elephant: ownership and community-organizational structure in primary care The New Zealand Medical Journal, 118 (2005), p. 1222

[20] R. Town, R. Kane, P. Johnson, M. Butler Economic incentives and physicians' delivery of preventive care: a systematic review American Journal of Preventive Medicine, 28 (2) (2005), pp. 234-240

[21] F. Jusot, Z. Or, N. Sirven Variations in preventive care utilisation in Europe European Journal of Ageing, 9 (1) (2012), pp. 15-25

[22] N. Goodwin, C. Perry, A. Dixon, C. Ham, J. Smith, A. Davies, et al. Integrated care for patients and populations: improving outcomes by working together The King's Fund, London (2012)

[23] D.N. Peikes, R.J. Reid, T.J. Day, D.D.F. Cornwell, S.B. Dale, R.J. Baron, et al. Staffing patterns of primary care practices in the comprehensive primary care initiative Annals of Family Medicine (2014), pp. 142-149, 10.1370/afm.1626

[24] J. Farmer, L. Iversen, N.C. Campbell, C. Guest, R. Chesson, G. Deans, et al .Rural/urban differences in accounts of patients' initial decisions to consult primary care Health \& Place, 12 (2006), pp. 210-221

[25] J.B. Kirby, T. KanedaNeighborhood socioeconomic disadvantage and access to health care Journal of Health and Social Behavior, 46 (1) (2005), pp. 15-31

[26] S.S. Nielsen, A. KrasnikPoorer self-perceived health among migrants and ethnic minorities versus the majority population in Europe: a systematic review International Journal of Public Health, 55 (5) (2010), pp. 357-371 
Vermeulen, L., Schäfer, W., Pavlic, D.R., Groenewegen, P.P. Community orientation of general practitioners in 34 countries. Health Policy: 2018, 122(10), 1070-1077

[27] S.M. Allen Gender differences in spousal caregiving and unmet need for care Journal of Gerontology, 49 (4) (1994), pp. S187-S195

[28] W.G.W. Boerma, A. Van den Brink-Muinen Gender-related differences in the organization and provision of services among general practitioners in Europe: a signal to health care planners Medical Care, 38 (10) (2000), pp. 993-1002

[29] S.J. Bartley, P.W. Blanton, J.L. Gilliard Husbands and wives in dual-earner marriages: decision-making, gender role attitudes, division of household labor, and equity Marriage \& Family Review, 37 (4) (2005), pp. 69-94 2005

[30] W.L. Schäfer, W.G. Boerma, D.S. Kringos, J. De Maeseneer, S. Gress, S. Heinemann, et al. Groenewegen PP. QUALICOPC, a multi-country study evaluating quality, costs and equity in primary care BMC Family Practice, 20 (October (12)) (2011), p. 115

[31] W.L. Schäfer, W.G. Boerma, D.S. Kringos, E. De Ryck, S. Greß, S. Heinemann, et al. Measures of quality, costs and equity in primary health care: instruments developed to analyse and compare primary care in 35 countries Quality in Primary Care, 21 (2) (2013), pp. 67-79

[32] P.P. Groenewegen, S. Gre $\beta$, W. Schäfer General practitioners' participation in a large, multicountry combined general practitioner-patient survey: recruitment procedures and participation rate International Journal of Family Medicine (2016), p. 4929432, 10.1155/2016/4929432

[33] D.S. Kringos, W.G.W. Boerma, Y. Bourgueil, T. Cartier, T. Dedeu, T. Hasvold, et al. The strength of primary care in Europe: an international comparative study British Journal of General Practice, 63 (2013), pp. e742-e750

[34] J. Healy, E. Sharman, B. Lokuge Australia: health system review Health Systems in Transition, 8 (5) (2006), pp. 1-158

[35] D. Gjorgjev, A. Bacanovic, S. Cicevalieva, Z. Sulevski, S. Grosse-Tebbe The former Yugoslav Republic of Macedonia: health system review Health Systems in Transition, 8 (2) (2006), pp. 1-98

[36] E. Mossialos, M. Wenzl International profiles of health care systems. Commonwealth fund 2016 Retrieved from (2015)

http://www.commonwealthfund.org/ /media/files/publications/fundreport/2016/jan/1857_mossialos_intl_profiles_2015_v7.pdf

[37] K. Armingeon, V. Wenger, F. Wiedemeier, C. Isler, L. Knöpfel, D. Weisstanner, et al. Comparative political data set 1960-2015 Institute of Political Science, University of Berne, Bern (2017)

[38] D. Kringos, W.G.W. Boerma, A. Hutchinson, R.B. Saltman (Eds.), Building primary care in a changing Europe, World Health Organization, European Observatory on Health Systems and Policies (2015)

[39] G.P. Marchildon Canada: Health system review Health Systems in Transition, 15 (1) (2013), pp. 1-179

[40] Gauld, R. The New Zealand Health Care System (n.d.). Retrieved April 12, 2017, from http://international.commonwealthfund.org/countries/new_zealand/.

[41] McCartney M. General Practice in England and Australia - a comparison (n.d.). Retrieved from http://www.gpinfo.co.uk/1.html.

[42] T. Gavagan A systematic review of COPC: evidence for effectiveness Journal of health care for the poor and underserved, 19 (3) (2008), pp. 963-980

[43] WHO Framing the health workforce agenda for the sustainable development goals; biennium report 2016-2017 World Health Organisation, Geneva (2017)

[44] J. Frenk, L. Chen, Z.A. Bhutta, J. Cohen, N. Crisp, T. Evans, et al. Health professionals for a new century: transforming education to strengthen health systems in an interdependent world Lancet, 376 (9756) (2010), pp. 1923-1958

[45] K.M. Connors, S.B. Cashman, S.D. Seifer, M. Unverzagt Advancing the healthy people 2010 objectives through community-based education: a curriculum planning guide Community Campus Partnerships for Health, San Francisco, CA (2003)

[46] S.K. Longlett, J.E. Kruse, R.M. Wesley Community-oriented primary care: critical assessment and implications for resident education Journal of the American Board of Family Medicine, 14 (2) (2001), pp. 141-147

[47] J. Gofin, G. Foz Training and application of community-oriented primary care (COPC) through family medicine in Catalonia, Spain Family Medicine, 40 (3) (2008), pp. 196-202 
Vermeulen, L., Schäfer, W., Pavlic, D.R., Groenewegen, P.P. Community orientation of general/ practitioners in 34 countries. Health Policy: 2018, 122(10), 1070-1077

[48] J.R. Brill, S. Ohly, M.A. Stearns Training community responsive physicians Academic Medicine, 77 (7) (2002), p. 747

[49] A.H. Strelnick Community-oriented primary care: the state of an art Archives of Family Medicine, 8 (6) (1999), p. 550

[50] J. De Maeseneer Family medicine and primary care: at the crossroads of societal change Lannoo Campus Publishers, Leuven (2017)

[51] C. Merzel, J. D'Afflitti Reconsidering community-based health promotion: promise, performance, and potential American Journal of Public Health, 93 (4) (2003), pp. 557-574

[52] W. Schäfer, W. Boerma, F. Schellevis, P. Groenewegen GP practices as a one-stop shop: how do patients perceive the quality of care? A cross-sectional study in thirty-four countries Health Services Research (2018), p. 201, 10.1111/1475-6773.127547

\section{BOX, TABLES AND FIGURES}

Fig. 1. Summary of hypotheses to explain variation in community orientation of GPs at different levels.

\section{Levels}

\section{countries}

\section{GPs}

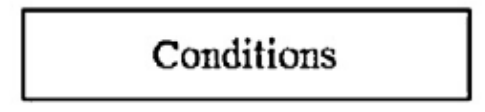

Outcome

health system characteristics, political composition and economic resources

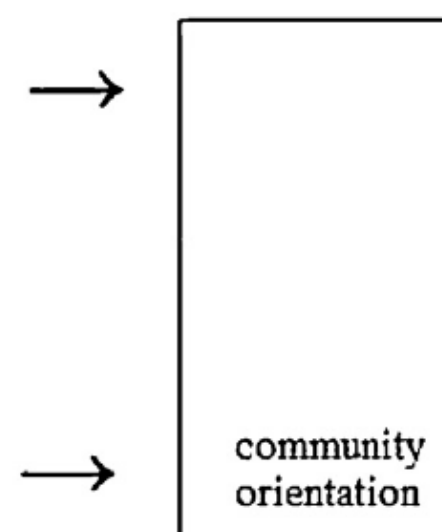

resources, methods, structure and task environment orientation

\section{practices}

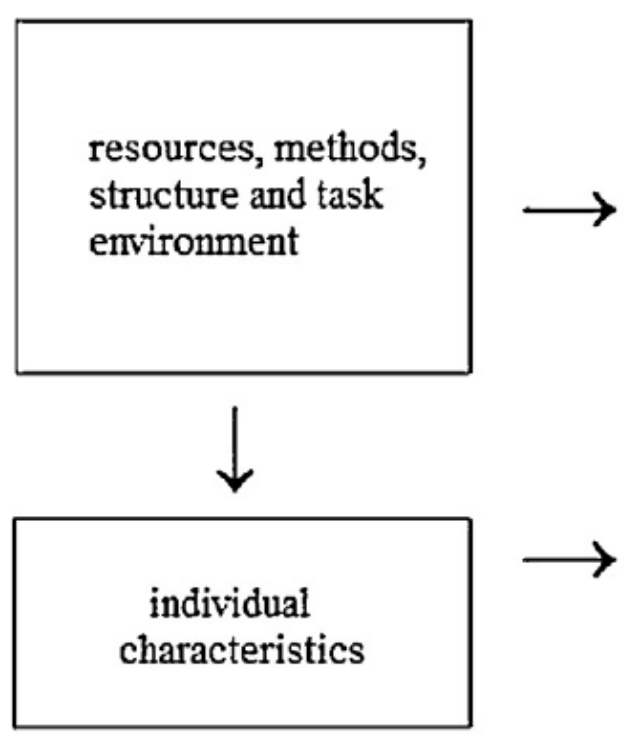


Vermeulen, L., Schäfer, W., Pavlic, D.R., Groenewegen, P.P. Community orientation of general practitioners in 34 countries. Health Policy: 2018, 122(10), 1070-1077

\begin{abstract}
Box 1 The QUALICOPC study.
The QUALICOPCstudy was co-funded by the European Commission under the so-called 'Seventh Framework Programme', and was led by a consortium of six research institutes from Belgium, Germany, Italy, the Netherlands and Slovenia. Data were collected in 31 European countries (26 EU countries, Iceland, Norway, Turkey, Switzerland and FYR Macedonia). Furthermore, research units from Australia, Canada and New Zealand have joined the study. Data collection focused on three levels: the health care system, the GP practice and patients. Data on the national primary care systems are derived from the Primary Health Care Activity Monitor Europe (PHAMEU). New information was collected through linked surveys among GPs (seen as the main providers of primary care), their patients and fieldworkers visiting GP practices. Answers to the questionnaires provide insight into the professional behaviour of GPs and the experiences of patients. In each country, the response target was 220 GPs (except for very small countries) and ten patients per GP. One GP per practice was invited to participate in the study. The questionnaires were translated in the national languages of the countries through an official forward- and back-translation procedure and in some languages of large ethnic minority groups. Ethical approval for the QUALICOPC study was acquired in accordance with the legal requirements in each country.
\end{abstract}

Table 1. Linear multilevel regression analysis (number of GPs $=7173$; number of countries $=34$ ); coefficients of GP/practice variables.

\begin{tabular}{|c|c|c|}
\hline & Model 0 & Model 2 \\
\hline & B (st.err.) & B (st.err.) \\
\hline \multicolumn{3}{|l|}{ Fixed part } \\
\hline Constant & $3.26(0.037)^{* * *}$ & $3.26(0.037)^{* * *}$ \\
\hline Age (continuous) & & $-0.001(0.001)$ \\
\hline Financial incentive for prevention (yes $=1$ ) & & $-0.013(0.017)$ \\
\hline Shared accommodation (yes $=1)$ & & $-0.039(0.016)^{* * *}$ \\
\hline Use of medical records to generate overviews $($ yes $=1)$ & & $0.062(0.015)^{* * *}$ \\
\hline Meetings with other PC professionals (continuous) & & $0.090(0.016)^{* * * *}$ \\
\hline \begin{tabular}{|l|} 
Advice from medical specialists (continuous) \\
\end{tabular} & & $0.10(0.028)^{* * * *}$ \\
\hline \multicolumn{3}{|l|}{ Urbanity (ref = big (inner) city) } \\
\hline - suburbs / (small) town & & $0.011(0.017)$ \\
\hline - mixed urban-rural / rural & & $0.072(0.018)^{* * *}$ \\
\hline \multicolumn{3}{|l|}{ Socially disadvantaged (ref = below average) } \\
\hline - average & & $-0.013(0.016)$ \\
\hline - above average & & $-0.000(0.020)$ \\
\hline \multicolumn{3}{|l|}{ Ethnic minorities (ref $=$ below average) } \\
\hline - average & & $0.024(0.016)$ \\
\hline - above average & & $0.048(0.021)^{* *}$ \\
\hline Preventive activities (continuous) & & $0.218(0.046)^{* * *}$ \\
\hline Other paid professional activities (yes $=1$ ) & & $0.042(0.016)^{* * *}$ \\
\hline Gender (female = 1) & & $-0.001(0.014)$ \\
\hline \multicolumn{3}{|l|}{ Employment status (ref = salaried) } \\
\hline - self-employed & & $0.058(0.023)^{* *}$ \\
\hline - mixed & & $0.105(0.067)$ \\
\hline \multicolumn{3}{|l|}{ Payment system (ref = capitation) } \\
\hline - salaried & & $-0.020(0.020)$ \\
\hline - salaried combined & & $0.019(0.023)$ \\
\hline
\end{tabular}


Vermeulen, L., Schäfer, W., Pavlic, D.R., Groenewegen, P.P. Community orientation of general practitioners in 34 countries. Health Policy: 2018, 122(10), 1070-1077

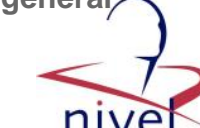

\begin{tabular}{|c|c|c|}
\hline & Model 0 & Model 2 \\
\hline & B (st.err.) & B (st.err.) \\
\hline - fee-for-service & & $0.014(0.026)$ \\
\hline \begin{tabular}{|l|} 
- other \\
\end{tabular} & & $-0.004(0.054)$ \\
\hline \multicolumn{3}{|l|}{ Random part } \\
\hline GP level variance & $0.2899(0.005)$ & $0.2827(0.005)$ \\
\hline Country level variance & $0.0443(0.011)$ & $0.0474(0.012)$ \\
\hline ICC & $13 \%$ & $14 \%$ \\
\hline
\end{tabular}

Fig. 2. Average community orientation of GPs of GPs in 31 European countries.

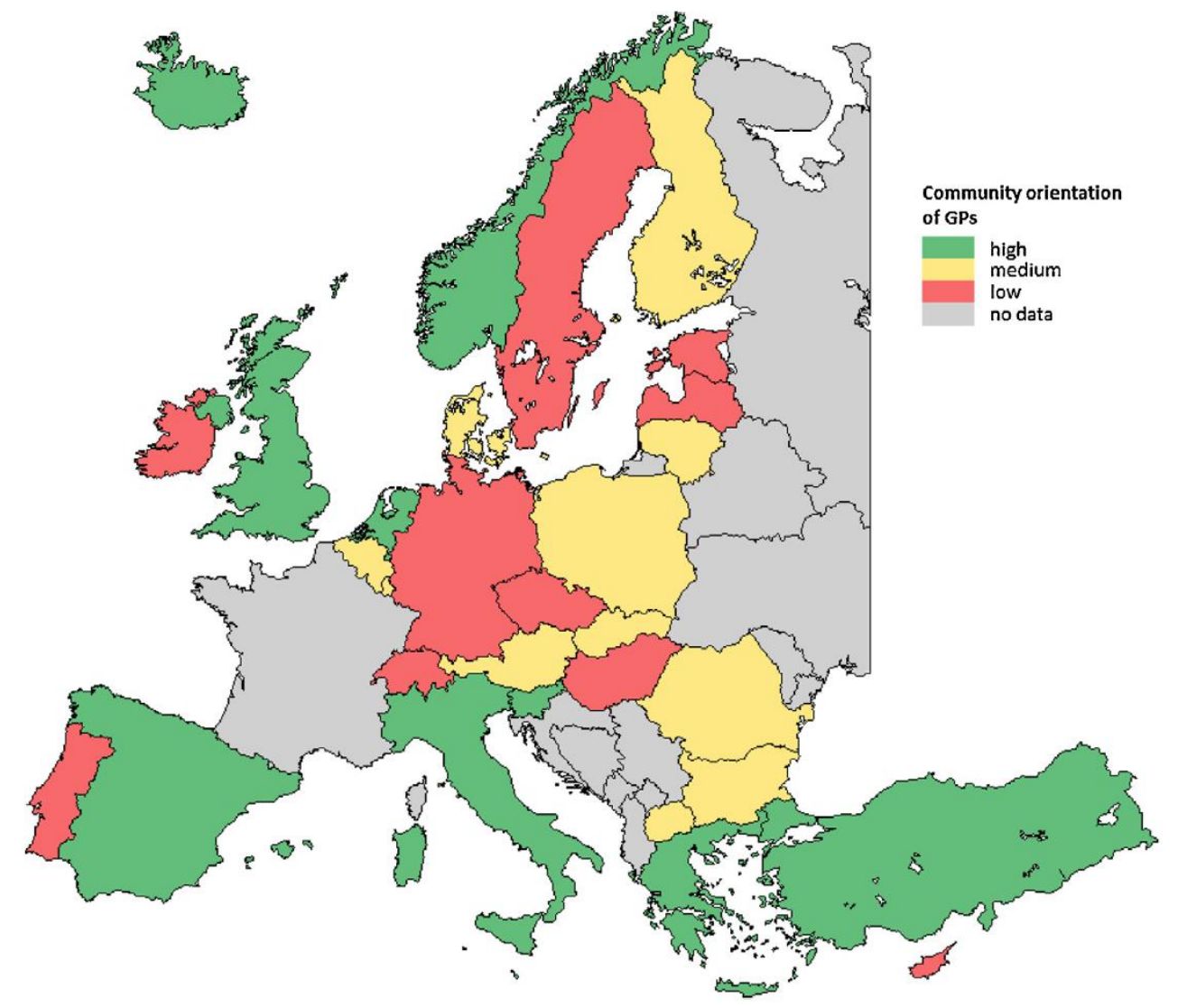


Vermeulen, L., Schäfer, W., Pavlic, D.R., Groenewegen, P.P. Community orientation of general practitioners in 34 countries. Health Policy: 2018, 122(10), 1070-1077

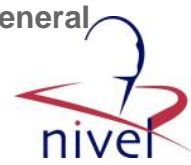

Table 2. Linear multilevel regression analysis (number of GPs $=7173$; number of countries $=34$ ); coefficients of country variables (models include GP/practice variables of Model 2).

\begin{tabular}{|c|c|c|c|c|c|}
\hline & Model 3 & Model 3 A & Model 3B & Model 3C & Model3D \\
\hline & B (st.err.) & B (st.err.) & B (st.err.) & B (st.err.) & B (st.err.) \\
\hline \multicolumn{6}{|l|}{ Fixed part } \\
\hline GDP/cap & $\begin{array}{r}0.000 \\
(0.000)\end{array}$ & $\begin{array}{r}0.000 \\
(0.000)\end{array}$ & $0.000(0.000)$ & $0.000(0.000)$ & $0.000(0.000)$ \\
\hline Strength of PC (continuous) & & $\begin{array}{r}0.315 \\
(0.256)\end{array}$ & & & \\
\hline \multicolumn{6}{|l|}{$\begin{array}{l}\text { Health care system } \\
\text { (ref }=\text { NHS) }\end{array}$} \\
\hline - social health insurance & & & \begin{tabular}{|c|}
-0.014 \\
$(0.095)$ \\
\end{tabular} & & \\
\hline - transitional & & & \begin{tabular}{|l}
-0.173 \\
$(0.102)^{*}$
\end{tabular} & & \\
\hline List system (yes $=1)$ & & & & $\begin{array}{l}0.0194 \\
(0.092)^{* *}\end{array}$ & \\
\hline \begin{tabular}{|l} 
Yrs of left government \\
(continuous)
\end{tabular} & & & & & $0.002(0.005)$ \\
\hline \multicolumn{6}{|l|}{ Random part } \\
\hline GP level variance & $\begin{array}{r}0.2827 \\
(0.005)\end{array}$ & $\begin{array}{r}0.2827 \\
(0.005)\end{array}$ & $\begin{array}{r}0.2827 \\
(0.005)\end{array}$ & $\begin{array}{r}0.2827 \\
(0.005)\end{array}$ & $\begin{array}{r}0.2827 \\
(0.005)\end{array}$ \\
\hline Country level variance & $\begin{array}{r}0.0484 \\
(0.012)\end{array}$ & $\begin{array}{r}0.0476 \\
(0.012)\end{array}$ & $\begin{array}{r}0.0469 \\
(0.012)\end{array}$ & $\begin{array}{r}0.0434 \\
(0.011)\end{array}$ & $\begin{array}{r}0.0490 \\
(0.012)\end{array}$ \\
\hline ICC & $15 \%$ & $14 \%$ & $14 \%$ & $13 \%$ & $! 5 \%$ \\
\hline
\end{tabular}

* $p<0.10$.

** $p<0.05$. 